\title{
Moeda única do Mercosul: notas para o debate ${ }^{1}$
}

\author{
FABIO GIAMBIAGI *
}

\begin{abstract}
“Os próprios projetos de integração regional, ao mesmo tempo em que tendem a comprometer as soberanias nacionais, expressam uma tendência à constituição de supra-soberanias que contradizem também os pressupostos da 'aldeia global'. A futura moeda única européia participa igualmente de ambos os fenômenos: vai comprometer as soberanias estatais no manejo de um dos pilares do Estado moderno, o instrumento monetário, mas vai criar também um padrão de medida de valor exclusivamente europeu, representando essa exclusividade um desafio econômico frente ao resto do mundo.”
\end{abstract}

(Rapoport, 1997, página 170).

\section{Introdução}

A proposta de unificação monetária entre os países do Mercosul, feita em Giambiagi (1997) e depois transformada em proposta oficial do Governo argentino, tem gerado, como era natural se esperar, algumas reações contrárias, tanto na Argentina como no Brasil. Não nos compete analisar aqui por que a proposta pode ser benéfica para a Argentina. Por outro lado, a argumentação em favor de uma agenda de convergência entre aqueles dois países - que seria depois estendia aos demais países membros do acordo regional - já foi feita em Lavagna e Giambiagi (1998). Assim, o presente artigo se destina, especificamente, a responder a algumas das críticas que começam a ser feitas à proposta de formação de uma área monetária unificada entre os países do Mercosul ou, alternativamente - talvez em uma primeira etapa -, entre Brasil e Argentina.

Há quatro esclarecimentos prévios que cabe fazer a respeito das características do texto. Primeiro, ele tem como marco de referência as objeções feitas à proposta através de menções esporádicas feitas aqui e acolá na imprensa, já que, sendo o tema muito recente, não se tem notícia ainda da existência de um debate acadêmico mais aprofundado sobre a matéria. Segundo, justamente em função disso, a apresentação dos argumentos contrários à proposta da moeda

Rev. Bras. Polít. Int. 41 (1): 24-39 [1998]

* Gerente de Macroeconomia do BNDES 
única para o Mercosul será feita por nós na base de deduções elaboradas a partir de argumentos apresentados muito sucintamente na imprensa, já que, pela natureza das matérias que esta publica, nela não há espaço para uma apresentação mais longa das idéias dos críticos. Terceiro, nossos argumentos, neste artigo, não procurarão responder a uma certa linha de argumentação contrária à proposta, baseada no fato de que os países do Mercosul não configuram uma área monetária ótima (optimum currency area - OCA), o que implicaria tratar de uma literatura específica da teoria econômica, provavelmente algo árida para o público de não economistas para o qual este artigo se destina. ${ }^{2} \mathrm{E}$ quarto, por último, o artigo, com exceção da sua última seção, não pretende ser propriamente uma defesa da moeda única em si - o que já foi feito no mencionado artigo de Giambiagi de 1997 -, mas apenas - como o seu título indica explicitamente - uma resposta a algumas das críticas feitas a ela.

O trabalho encontra-se organizado em quatro seções. Depois desta introdução, são sintetizadas as críticas feitas à proposta de unificação monetária entre os países do Mercosul, após o que se tenta argumentar contra essas críticas, na seção posterior. Finalmente, faz-se algumas reflexões finais, à guisa de conclusão.

\section{As críticas à moeda única no Brasil ${ }^{3}$}

Para efeitos da organização dos argumentos deste trabalho, as críticas à proposta de uma moeda única para o Mercosul podem ser agrupadas, do nosso ponto de vista, em três categorias:

* Críticas quanto ao timing da proposta.

* Críticas baseadas em afirmações corretas, mas que não invalidam a proposta.

* Críticas, na nossa opinião, incorretas à proposta.

Essas três categorias, no seu conjunto, dão origem a uma lista de 12 argumentos que foram sendo apresentados através da imprensa, a partir da divulgação da proposta de unificação monetária. Tais argumentos são mencionados a seguir. Analisaremos, inicialmente, o primeiro tipo de crítica, que configura uma objeção quanto ao momento adequado da proposta de união monetária, embora não quanto ao seu mérito.

a) Natureza prematura da proposta. Conforme essa crítica, a moeda comum teria que ser considerada apenas como o último passo de um processo de integração, e só deveria vir a ser adotada após uma maior integração dos países, o que incluiria a eliminação nas arestas que ainda marcam a formação da área de livre comércio; o fim das listas de exceção à Tarifa Externa Comum (TEC); a harmonização das legislações nos campos trabalhista, tributário e de mercado de capitais; e, a integração dos sistemas financeiros. ${ }^{4}$ A unificação monetária européia só estaria 
ocorrendo depois de várias décadas de integração e em um estágio muito mais avançado de integração regional que o dos países do Mercosul. Antes de que tais requisitos sejam cumpridos, não estariam dadas as condições para a adoção de uma moeda única na região.

b) Escasso grau de abertura intra-regional. O comércio intra-regional mal representa algo em torno de 20 \% do comércio total dos países do Mercosul, o que está bastante aquém das proporções atingidas por esse tipo de comparação no caso dos países da Europa Ocidental. Em tais condições, não faria sentido renunciar à parcela de soberania associada à perda da moeda nacional, devido à natureza ainda precária e incipiente dos vínculos com os parceiros da região.

Quanto às afirmações corretas que servem de base para objeções à proposta de unificação monetária, mas que na nossa opinião não invalidam a mesma, são as que listamos a seguir.

c) Heterogeneidade dos interesses nacionais. Os interesses dos países do Mercosul, notadamente de Brasil e Argentina, seriam diferentes entre si. Basicamente, o Brasil teria um comércio mais diversificado e seria uma potência econômica em si, enquanto que a Argentina seria vista como um país menor, preocupado com a "Brasil dependência” e com desejo de evitar uma mudança da paridade relativa entre as respectivas moedas nacionais, em favor da competitividade das exportações brasileiras.

d) Heterogeneidade interna da sociedade. Ao contrário do caso dos países europeus que deverão integrar a zona do euro, e nos quais "a integração federativa é a projeção da integração econômica e social já realizada em cada país” (Serra, 1998), o Brasil - e, em maior ou menor grau, os demais países do Mercosul - seria um país no qual "a heterogeneidade estrutural e a pobreza estão longe de ser periféricas, como na Europa Ocidental” (Serra, 1998).

e) Peso excessivo dos países menores. Um dos problemas do baixo grau de institucionalidade do Mercosul é o elevado peso da opinião dos dois sócios menores - Paraguai e Uruguai -, o que criaria alguns percalços às negociações comerciais, do ponto de vista dos interesses brasileiros. Para o Brasil, portanto, seria um equívoco grave renunciar a parcela de sua soberania, tendo que compartilhá-la com dois países pequenos cujos PIBs, mesmo somados, não chegariam a representar $3 \%$ do PIB brasileiro.

f) Caráter de global trader do Brasil. Este é um argumento em parte complementar ao de (c). O Brasil seria um país com um grau de diversificação de 
mercados e de produtos da sua pauta de exportações que faria com que o seu interesse primordial fosse o de negociar com os diversos blocos comerciais, de modo a extrair o máximo de vantagens, ao invés de se fechar nos termos de um único acordo específico. Ao mesmo tempo, esse caráter o tornaria menos vulnerável do que os seus vizinhos em relação à existência de choques adversos de preços sobre o conjunto das suas exportações.

g) Falta de relação entre as estruturas produtivas de Brasil e Argentina. Este ponto seria complementar com os dois anteriores. A idéia é que o Brasil teria uma economia muito mais sólida e complexa do que a Argentina, com muito mais a perder do que o país vizinho, em caso da adoção de uma política cambial rígida, que pudesse afetar negativamente o seu setor exportador. No caso do Brasil, em particular, a proposta pode ser sintetizada na idéia de que a estrutura produtiva do país não permite que ele se dê ao luxo de renunciar à política cambial.

h) Congestionamento da agenda de negociações do país. A agenda de negociações do Brasil estaria carregada atualmente, inclusive com o próprio Mercosul, envolvendo questões setoriais - açúcar, leite, etc. -, listas de exceção à TEC, ALCA, etc.. Em tais circunstâncias, incluir um tema denso como seria o das negociações que, no limite, conduzissem a uma unificação monetária, seria um problema, comprometendo as demais negociações nas quais o país está envolvido.

Por último, restam as críticas que nos parecem simplesmente equivocadas, em função da linha de contra-argumentação que iremos desenvolver na próxima seção. Tais críticas são expostas na continuação.

i) Interesse argentino na proposta. A proposta argentina de postular a meta de unificação monetária na região do Mercosul é entendida por alguns analistas como algo que visaria apenas permitir à Argentina sair da convertibilidade, não fazendo sentido que o Brasil se atrelasse a esse desejo, por motivos que estariam ligados conforme a linha de argumentação de crítica à proposta -, estrita e exclusivamente, à economia argentina. Em termos algo pejorativos, poder-se-ia sintetizar este argumento na idéia de que "o Brasil não pode renunciar à sua soberania só para resolver os problemas da Argentina”.

j) Ausência de interesse do Brasil. Complementarmente a (i), alega-se que o Brasil não teria nada a ganhar em caso de unificação monetária, dado que renunciaria a parcela da sua soberania, sem obter maiores benefícios em troca.

k) Interesse meramente político do Mercosul para o Brasil. Enquanto que o Mercosul teria uma importância significativa para a economia argentina - e muito 
maior ainda para as economias paraguaia e uruguaia -, "para o Brasil o Mercosul é sobretudo um objetivo político” (Serra, 1998).

\section{l) Caráter despropositado da limitação fiscal associado a critérios como o} de Maastricht. Como se imagina que, caso os países-membro do Mercosul postulem uma meta de unificação monetária, isso viria acompanhado, entre outras coisas, de tetos "maastrichtianos" - ainda que talvez com parâmetros diferentes para os respectivos déficits fiscais medidos como proporção do PIB, isso faria o Brasil abrir mão, pelo menos parcialmente, da sua autonomia na determinação da sua própria política fiscal, o que, dado o peso relativo da economia brasileira no contexto do Mercosul, seria, na visão mais radical da denúncia da proposta, "um verdadeiro despropósito" - o que, de forma menos contundente, pode ser entendido como algo que tem uma relação custo-benefício elevada.

Passaremos agora a tentar rebater os argumentos acima mencionados, o que procuramos fazer na seção 3.

\section{Resposta às críticas}

Nesta seção, procura-se contra-argumentar os pontos apresentados na seção anterior, em ordem seqüencial.

a) Natureza prematura da proposta. A rigor, isto não chega a ser uma crítica, já que mesmo os defensores da proposta de unificação monetária reconhecem que é preciso que esta só ocorra após cumprida uma série de requisitos de maior coordenação macroeconômica entre as economias e de harmonização das respectivas legislações. Esse timing foi, inclusive, de alguma forma endossado pelo Presidente da República, Fernando Henrique Cardoso, quando, por ocasião da entrevista à imprensa em que o Presidente da Argentina, Carlos Menem, mencionou pela primeira vez a idéia da unificação monetária em público, no final de abril de 1997, o Presidente brasileiro comentou que: "Chegará o momento, mais adiante, para uma moeda comum, e a convergência de políticas macroeconômicas". ${ }^{5}$ A questão a resolver, portanto, não seria discutir se a moeda comum é uma meta boa ou não para ser atingida e, sim, em que momento começar a trabalhar, com que cronograma e com que margem em relação às concessões que cada país está disposto a fazer, para que a proposta de moeda única possa se transformar em realidade algum dia. Nesse sentido, embora seja claramente prematuro pensar em criar algo similar ao que foi, por exemplo, o Instituto Monetário Europeu (IME) no início do processo que deverá levar à integração monetária européia, a tese oposta, de que o tema não deve entrar na agenda diplomática dos países da região, também não nos parece correta, já que encerra o risco de "congelar" o Mercosul nos termos atuais, com os riscos a isso associados. ${ }^{6}$ 
Há que se lembrar, também, que a comparação entre as 4 décadas de história da unificação européia e a ainda curta história de integração do Mercosul é, em parte, improcedente. Em primeiro lugar, porque a velocidade de transformações da economia mundial não comporta que se trabalhe com os prazos do passado: as mudanças que ocorreram no mundo, na tecnologia e na economia em geral nos últimos 10 anos foram muito mais rápidas e intensas do que as que tinham se verificado em décadas anteriores. Isso significa que o custo de não avançar é muito maior. Em segundo lugar, porque, embora a Europa só irá ter uma moeda circulando fisicamente a partir de 2002, o debate acadêmico sobre uma moeda única européia começou nos anos 60 , menos de 10 anos depois da assinatura do Tratado de Roma e transbordou para diplomacia no início dos anos 70, só não prosperando no restante da década devido ao desmantelamento do sistema de Bretton Woods e aos efeitos perversos do primeiro choque do petróleo sobre a inflação internacional. E, por último, porque se a moeda comum do Mercosul vier a se tornar realidade, isso, provavelmente, ocorrerá em torno de 2015, ou seja, 30 anos depois dos acordos pioneiros de integração de 1986 entre Brasil e Argentina - o que configura um período histórico não desprezível - e mais de 20 anos depois dos planos de estabilização de Argentina (1991) e Brasil (1994). Portanto, o fato de que uma moeda única da região seja prematura hoje não significa que não possa ser viável daqui a 15 anos - para o que é necessário começar a trabalhar a partir de agora.

b) Escasso grau de abertura intra-regional. Também neste caso, entende-se que a objeção não é quanto à proposta em si e, sim, quanto à conveniência de adotar uma moeda única, quando o grau de abertura intra-regional é ainda baixo. A respeito disto, porém, há algumas questões a considerar. Primeiro, o fato de que essa abertura é ainda baixa, mas tem sido quase sistematicamente crescente desde a origem do Mercosul, sendo válido admitir que deva continuar a aumentar nos próximos anos (ver Tabela 1). ${ }^{7}$ Conseqüentemente, como a moeda única não é uma proposta para ser adotada imediatamente e, sim, em um horizonte de longo prazo, quando isso ocorrer, o grau de abertura intra-regional deverá ser, provavelmente, maior do que o atual.

Segundo, como destacado em Frankel e Rose (1997), em relação ao caso europeu, mas de forma que se aplica a outras situações, a aderência de um grupo de países aos critérios que definem as condições ideais para adotar uma única moeda é endógena a essa mesma decisão: “A country could fail the optimum currency area (OCA) criteria for membership today, and yet, if it goes ahead and joins anyway, could, as the result of joining, satisfy the OCA criteria in the future... Some countries may appear, on the basis of historical data, to be poor candidates for European Monetary Union (EMU) entry. But EMU entry per se... may provide a substantial impetus for trade expansion.... That is, a country is more likely to 
satisfy the criteria for entry into a currency union ex post than ex ante" (Frankel e Rose, 1997, páginas 67/68, grifos nossos).

Tabela 1

\section{Brasil - Participação das exportações ao Mercosul nas exportações totais (\%)}

\begin{tabular}{lc}
\hline Ano & Participação (\%) \\
\hline 1990 & 4,2 \\
1991 & 7,3 \\
1992 & 11,5 \\
1993 & 14,0 \\
1994 & 13,6 \\
1995 & 15,3 \\
1996 & 15,5 \\
1997 & 17,1 \\
\hline
\end{tabular}

Fonte: Banco Central do Brasil.

c) Heterogeneidade dos interesses nacionais. Esta heterogeneidade é verdadeira, mas não invalida a possibilidade da unificação monetária. A maioria das análises a respeito do caso europeu coincide em afirmar que Maastricht foi o resultado de um compromisso entre o interesse da França de compartilhar as decisões econômicas a respeito da Europa com a Alemanha - ao invés de ficar a reboque das decisões do Bundesbank - e o interesse da Alemanha de dar um sinal claro aos seus parceiros de que a unificação com a Alemanha Oriental não implicaria a retomada do antigo expansionismo germânico, para o que o país considerava importante a reafirmação dos laços especiais com a Europa, através de um passo decisivo para a integração, como é o da unificação monetária. A isso se juntou o desejo dos países do Club Med - Itália, Espanha e Portugal - de se beneficiarem da "importação de credibilidade" propiciada pelo euro, o que significará a virtual eliminação da influência dos seus respectivos track records na determinação das taxas de juros dessas economias, com impacto favorável sobre os níveis de atividade e de emprego. Tal heterogeneidade não impediu, contudo, que o Tratado de Maastricht esteja a ponto de dar origem, pouco mais de 6 anos depois da sua assinatura, a uma moeda comum para um grupo de mais de 10 países entre os membros da "Europa dos 15". Da mesma forma, a existência de interesses diferenciados entre Brasil e Argentina não deve ser entendida como óbice para que a moeda comum entre ambos possa algum dia se transformar em realidade. 
d) Heterogeneidade interna da sociedade. Esta é uma realidade inegável, que, entretanto, também não invalida a proposta de que este artigo trata, na nossa opinião. Há duas perguntas que cabe fazer a respeito. Primeiro, a moeda única pode contribuir para diminuir essa heterogeneidade? A resposta é sim, mediante o maior estímulo que poderia representar para a realização de investimentos, em uma área que passaria a ser vista como sinônimo de consolidação da estabilidade econômica. A segunda pergunta é: essa heterogeneidade prejudicou os países da Europa que deverão aderir ao euro? A resposta, claramente, é não. Quando a Espanha aderiu à, então, Comunidade Econômica Européia (CEE), era um país ainda muito atrasado com relação ao nível de desenvolvimento do resto da Europa, mas tomou essa opção consciente de que a integração era a melhor forma de superar esse atraso, com resultados excelentes, a olhos vistos, à luz do retrospecto econômico do país nos últimos 15 anos. Isso ocorreu apesar de ter indicadores de pobreza muito maiores que os da Alemanha ou França, por exemplo; regiões do país inteiramente atrasadas em termos econômicos; e um problema de regionalismo separatista que, no Brasil, não existe, fatores esses que não impediram que a Espanha seja um dos países que constará da primeira rodada de adesões ao euro. Em maior ou menor medida, comentários similares aplicam-se também aos outros dois membros do Club Med - Portugal e Itália.

e) Peso excessivo dos países menores. Isto, realmente, pode se converter em um problema, mas a solução é muito simples e é fazer com que o peso predominante nas decisões a serem tomadas nos organismos conjuntos - notadamente, no Banco Central unificado que teria que ser criado - caiba a Brasil e Argentina.

f) Caráter de global trader do Brasil. O país tem de fato uma estrutura diversificada da sua pauta de exportações que faz com que se diferencie dos demais países do bloco, inclusive da Argentina. Isso não impede, porém, que o país identifique que, entre as diversas negociações em que está envolvido, no contexto de um mundo dividido em áreas regionais, os sócios privilegiados devem ser os que compõem a sua mesma área de influência. Por outro lado, cabe lembrar que entre a decisão de integrar uma área monetária comum e o início da vigência da nova moeda transcorreria um período da ordem de uma década. Nesse intervalo, a Argentina poderia se empenhar em diversificar a sua pauta de exportações, no sentido de diminuir o impacto de eventuais choques negativos sobre o Balanço de Pagamentos do bloco.

g) Falta de relação entre as estruturas produtivas de Brasil e Argentina. Em relação a este ponto, vale a observação feita no item (f) acima, no sentido de que a Argentina disporia de tempo para que a sua estrutura industrial fosse mais diversificada. Por outro lado, como, mantidas as tendências atuais - com o Banco 
Central do Brasil continuando a ajustar a taxa de câmbio nominal ligeiramente acima da inflação ao longo de alguns anos -, o Brasil chegaria à unificação monetária com uma taxa de câmbio real mais desvalorizada do que a atual, a rigor o problema estaria colocado não para o Brasil e, sim, para a Argentina, que teria que identificar mecanismos apropriados para promover alguma desvalorização real, ainda que gradual, para não chegar à eventual unificação com o seu setor externo desajustado.

h) Congestionamento da agenda de negociações do país. Esta é uma realidade. O problema é que, analisando o quadro que se tema pela frente, dificilmente tal congestionamento vai se alterar a médio prazo. Isto porque: i) a agenda da negociação da ALCA tende a ser cada vez mais densa a medida que nos aproximemos de 2005; ii) o tema de um acordo de livre comércio entre o Mercosul e a União Européia passará a tomar um espaço maior na agenda brasileira; e, iii) existe a possibilidade da realização de uma "rodada do milênio", que complemente a "rodada Uruguai" que deu origem à Organização Mundial de Comércio (OMC) e às decisões tomadas paralelamente à criação desta. Portanto, o mesmo argumento do "congestionamento da agenda externa do país" poderá existir daqui a 3, a 4 ou a 7 anos, o que acarreta o risco de "congelar" o Mercosul, já citado no item (a) desta seção.

i) Interesse argentino na proposta. Há, quanto à idéia de que o que a Argentina quer é apenas encontrar uma forma de sair da convertibilidade, na nossa opinião, um equívoco de interpretação. Isto porque: i) o fim da convertibilidade é ainda um tema tabu na Argentina, onde a memória dos três "surtos" de hiperinflação de 1989/1990 ainda está muito fresca e nenhum agente político ou econômico relevante no debate econômico está propugnando pela medida; ii) os próprios argentinos estão divididos a respeito da matéria, sendo um exagero se falar em "interesse dos argentinos” como se a proposta fosse algo que congregasse um apoio unânime da sociedade; e, iii) todas as indicações são de que a orientação oficial em favor da proposta partiu da área política do Governo e não da sua área econômica, sendo difícil imaginar que tais considerações de longo prazo a respeito de uma estratégia de saída da convertibilidade tenham tomado parte no processo decisório.

j) Ausência de interesse do Brasil. Esta crítica deixa de levar em conta uma dimensão fundamental da proposta, que é o fortalecimento da região como um todo. Atualmente, a região composta pelos países do Mercosul ainda luta, na sua tentativa de atrair capitais externos, contra o retrospecto associado à "marca" da América Latina, de inequívoca conotação negativa, em função da sua história de governos instáveis, alta inflação e da crise dos anos 80. Se, no contexto de uma unificação monetária dos países da região, esta passar a ser vista pelos investidores como sinônimo de estabilidade democrática, inflação baixa e déficits fiscais sob 
controle, as chances de que a região receba um fluxo contínuo de investimentos externos maiores do que hoje cresceriam naturalmente. Ora, parece claro que, em tais circunstâncias, com as economias de escala que adviriam da existência de um mercado ampliado e sem a barreira da incerteza cambial no interior deste, o país que mais se beneficiaria da maior atratividade da região como um todo seria o Brasil. Primeiro, pelo seu tamanho, que operaria como catalisador natural de investimentos. Segundo, pela sua posição geográfica, mais central que a dos demais vizinhos. Terceiro, porque, na comparação com a Argentina, é quem mais se ressente dessa imagem negativa, já que a sua estabilização é mais recente, seu déficit fiscal é maior e o seu rating externo pior. Por último, nesse contexto, as taxas de juros se aproximariam das internacionais, algo que para a economia brasileira implicaria uma melhora substancial, muito maior do que para a argentina, que já se encontra mais próxima desses níveis.

k) Interesse meramente político do Mercosul para o Brasil. Trata-se, na nossa opinião, de uma visão que não leva em conta as transformações operadas na situação da economia brasileira em função do próprio crescimento do Mercosul. Em 1990, a participação das exportações do Brasil para os EUA era de 24,4 \% das exportações totais brasileiras, proporção essa que caiu para 17,8 \% do total em 1997. No caso do Mercosul, conforme mostrado na Tabela 1, a participação evoluiu de 4,2 para 17,1 \% do total no mesmo período, sendo que nas exportações de manufaturados, especificamente, as vendas para o Mercosul já respondem por mais de 1/4 (27,9 \%) das exportações desses bens, acima da participação das vendas de manufaturados aos EUA (21,2 \% das exportações de manufaturados). Não nos parece correto, portanto, julgar que, à luz desses números, o Mercosul tenha apenas uma importância política para o Brasil, mais ainda considerando que, mantida tal tendência, provavelmente até o final da década, a região como um todo vai se transformar no principal destino para nossas exportações, se comparada com os demais países do mundo, tomados individualmente.

\section{l) Caráter despropositado da limitação fiscal associado a critérios como o} de Maastricht. Trata-se de uma avaliação impregnada de um forte conteúdo emocional - associado à noção de perda de soberania -, a respeito da qual é difícil se manifestar. Entretanto, há dois fatores que, na nossa opinião, deveriam ser considerados. O primeiro, que de qualquer forma o Brasil simplesmente tem que implementar um forte ajuste fiscal nos próximos anos, sob pena de que, concluída a privatização - que permite conciliar a existência de déficits fiscais elevados, com uma certa estabilidade do endividamento público consolidado -, a relação dívida pública/PIB assuma uma trajetória sistematicamente crescente, com todas as conseqüências disso decorrentes, o que no limite implicaria o fim do Plano Real. ${ }^{8}$ $\mathrm{O}$ segundo, que a falta de um compromisso rígido com metas fiscais de médio 
prazo de declínio do déficit público é um dos fatores que explica o fracasso das autoridades brasileiras em obter uma melhoria sistemática, duradoura e consistente dos resultados do setor público. ${ }^{9}$ Isto porque, na ausência de uma restrição fiscal efetiva como a que, por exemplo, existe atualmente na Europa, submetida ao budget constraint dos tetos de Maastricht, o Governo não tem tido um instrumento no qual se escudar para resistir às pressões por mais gastos, o que faz com que inexista a figura de uma "camisa de força" que condicione a execução da política fiscal. Em tais condições, o traçado de metas fiscais informais por parte do Governo acaba não tendo muita força como fator de resistência às pressões localizadas dos diferentes setores da sociedade e, na prática, não tem se verificado uma restrição orçamentária que efetivamente funcione como uma barreira contra o excesso de gasto. A existência de um acordo externo que o país tivesse que honrar, em benefício da integração regional - com as vantagens a isso associadas em termos de fortalecimento do país enquanto parte de uma região mais forte no cenário mundial -, seria, então, uma ajuda importante para as autoridades fiscais do Governo.

\section{Comentários finais}

Há cinco fatores que devem ser levados em consideração para entender a racionalidade da proposta sobre unificação monetária entre os países do Mercosul. Primeiro, uma unificação monetária cria economias de escala para os países que dela formam parte, pois potencializa ao máximo os ganhos associados a uma área de livre comércio, ao eliminar a barreira representada pela incerteza acerca das paridades cambiais entre os países dessa área (Mundell, 1997).

Segundo, um dos motivos da criação do Mercosul foi o propósito de transformá-lo em um espaço regional que pudesse, a partir da formação de uma área de livre comércio, funcionar como uma base para a geração de plataformas de exportação - ainda que fortemente enraizadas no mercado interno regional. Este propósito, entretanto, ainda não foi concretizado, entre outras coisas porque as economias da escala, que supostamente decorreriam do Mercosul e que permitiriam a redução de custos necessária para incrementar a competitividade dos países do acordo, são limitadas pela incerteza cambial, conforme comentado acima. A eliminação dessa incerteza, base para a criação de um mercado efetivamente unificado, seria, então, um importante fator de incentivo à realização de novos investimentos, os quais estão condicionados à escala de produção e que, se concretizados, poderiam permitir à região como um todo a produção de novos excedentes exportáveis.

Terceiro, é preciso entender que um dos maiores riscos de não avançar ainda que lenta e gradualmente - na direção de uma unificação monetária na região é que o processo de integração seja contido e, no limite, passe por uma regressão, devido ao crescimento das tensões que resultam de não enquadrar as 
relações entre os países no contexto de um comprometimento inequívoco com o avanço da integração. Esse risco de retrocesso da integração é abordado por Roberto Bouzas com as seguintes palavras: "Los procesos de integración funcionan como una bicicleta: la única manera de no caer es avanzar permanentemente. La razón de esta afirmación está basada en una simple regla de economía política: si la agenda se congela los sectores afectados pueden organizarse y operar más efectivamente que si el horizonte se desplaza de una manera continua” (Bouzas, 1996, página 79). A multiplicação de atritos recentes no relacionamento bilateral entre Brasil e Argentina acerca de temas comerciais - como os casos dos remédios, do açúcar e do leite - parece fundamentar tais temores. É claro que "avançar no processo de integração" não significa, necessariamente, ter uma moeda comum o próprio Bouzas, nesse comentário, está distante de propor isso -, mas também é certo que nada pode ser mais revelador do compromisso político dos países com a integração do que o reconhecimento de que essa é a meta que se deseja atingir.

Quarto, conforme frisado por Rapoport na frase acerca da constituição de "supra-soberanias" que abre nosso artigo, a renúncia parcial à soberania que implica todo processo de integração - e quanto mais este avança, maiores são as "parcelas" de soberania de que um país abre mão - tem, como contrapartida, o fortalecimento, no contexto internacional, da região à qual o país pertence. A literatura européia recente sobre o processo de integração monetária deflagrado pelo Tratado de Maastricht destaca que, por exemplo, a França, embora "perca" soberania ao se integrar a uma área onde o franco desaparecerá, beneficia-se do fato de que a Europa - na qual o país é peça central -, com uma moeda unificada, vai pesar muito mais na economia mundial do que pesa atualmente, com uma grande diversidade de moedas nacionais. Nesse sentido, parece claro que, se o Mercosul atingir a maturidade suficiente para ter uma única moeda, o fortalecimento da região no panorama internacional será uma das principais conseqüências desse fato.

Quinto, um dos motivos que, do ponto de vista nacional, nos parece que deve induzir ao estabelecimento de uma meta de unificação monetária para o Mercosul, em um horizonte de 15 a 20 anos, é a necessidade de chegar a uma definição a respeito de que papel o país pretende ter na economia mundial, daqui a uma ou duas décadas. $O$ Brasil tem adotado uma atitude relativamente defensiva, nos últimos anos, acerca das principais negociações em que esteve ou está envolvido, notadamente no caso da ALCA - onde a postura adotada segue o critério de protelar o início do processo - e do Mercosul - onde, confrontadas diante da idéia argentina de propor uma meta de unificação monetária, as principais autoridades, à luz do que se depreende da leitura da imprensa escrita, tiveram uma reação bastante fria. Tais posturas, individualmente consideradas, são plenamente compreensíveis e, de certa forma, justificadas, em função da necessidade de preservar os interesses da indústria nacional - no caso da ALCA - e da evidente 
ausência de pré-condições para definir desde já um cronograma que leve até a moeda única - no caso do Mercosul. O problema é que, enquanto isso, o mundo continua em mutação.

Qual é, à luz disso, o futuro que se pode vislumbrar para o mundo daqui a uma ou duas décadas? Provavelmente, teremos: a) o NAFTA consolidado e o México muito mais integrado do que hoje à economia dos EUA; b) a ALCA plenamente constituída, representando uma área de livre comércio continental, indo do Alasca à Terra do Fogo; c) a Europa Ocidental, transformada em potência em condições de rivalizar com os EUA e "engordada” pela incorporação de novos membros à União Européia (UE) que, mais cedo ou mais tarde, acabará por se converter em uma região de mais de 20 países, com uma única moeda, o que pode até vir a fazer desaparecer - no sentido econômico associado à noção de “economias emergentes" - o conceito de "Europa oriental”;10 e, d) a Ásia, superadas as seqüelas da recente crise, novamente convertida em uma área dinâmica da economia mundial, com níveis crescentes de desenvolvimento e integração - pelo fortalecimento da ASEAN - e com a China plenamente convertida aos princípios de funcionamento de uma economia capitalista dinâmica. Nesse contexto, a pergunta que cabe fazer não é: "O que o Brasil tem a ganhar com a criação de uma moeda única do Mercosul?” e sim: “O que o Brasil tem a ganhar, mantendo uma postura isolada, no contexto de um mundo dividido em blocos, ao invés de fortalecer o acordo regional do qual ele é peça-chave?”. Note-se que “deixar de fortalecer" significa, neste caso, provavelmente, condenar esse acordo regional ao desaparecimento, pela sua "diluição" no espaço de uma área de livre comércio muito maior. Em outras palavras, não fortalecer o Mercosul - onde o peso do Brasil, por motivos óbvios, é grande - poderá significar na prática, para o Brasil, no contexto mundial da década de 2010, ficar a reboque da ALCA - onde a voz predominante será a dos EUA. O crucial é entender que o que vai acontecer com o Mercosul na década de 2010 depende das decisões estratégicas que forem tomadas ou deixarem de ser tomadas na década de 1990.

Por último, à guisa de síntese, há duas preocupações que devem nortear o debate incipiente sobre a moeda única, associadas a dois riscos opostos. É preciso evitar, ao mesmo tempo: a) a adoção de um cronograma irrealista, que postule, por exemplo, uma unificação monetária para a próxima década, o que não nos parece viável e pode conduzir a proposta ao fracasso; e, b) a passividade, que, sob o argumento de que ainda é prematuro estabelecer uma meta da moeda única no Mercosul, implique, na prática, não fazer nada para que esse objetivo deixe de ser prematuro, passividade essa que encerra os riscos comentados acima nesta mesma seção. Como declarou, realisticamente, o Secretário de Assuntos Internacionais do Ministério da Fazenda do Brasil, "Sabe-se que este [a moeda comum] será o fim da história, mas ninguém sabe como ou quando". ${ }^{11}$ Diante disso, a postura 
mais adequada, parece-nos, deve ser a de começar a agir para que essa meta possa ser atingida, em algum momento que não seja nem irrealisticamente prematuro, nem perigosa e desnecessariamente distante.

Março 1998

\section{Bibliografia}

ABREU, Marcelo de Paiva. "Financial integration in the MERCOSUR countries". Revista Integración y Comercio, INTAL, janeiro/abril, 1997.

BOUZAS, Roberto. "La agenda económica del MERCOSUR: desafíos de política a corto y mediano plazo”. Revista Integración y Comercio, INTAL, janeiro/ abril, 1996.

FRANKEL, Jeffrey e ROSE, Andrew. "The endogeneity of the optimum currency areas”. in BLEJER, Mario et alii (editores), Optimum Currency Areas New Analytical and Policy Developments. International Monetary Fund, 1997, capítulo 4.

GIAMBIAGI, Fabio. "Uma proposta de unificação monetária dos países do Mercosul”. Revista de Economia Política, outubro/dezembro, 1997.

LAVAGNA, Roberto e GIAMBIAGI, Fabio. "Hacia la creación de una moneda común - Una propuesta de convergencia coordinada de políticas macroeconómicas en el Mercosur”. Texto para Discussão, BNDES, março, 1998.

MUNDELL, Robert. "Updating the agenda for Monetary Union”. in BLEJER, Mario et alii (editores), Optimum Currency Areas - New Analytical and Policy Developments. International Monetary Fund, 1997, capítulo 2.

RAPOPORT, Mario. “Os Estados nacionais frente à globalização”. Revista Brasileira de Política Internacional, Instituto Brasileiro de Relações Internacionais, ano 40, número 2, 1997.

SERRA, José. “ECUs e Bupas”; Folha de São Paulo, 2 de março, 1998.

\section{Notas}

1 O autor agradece os comentários de Bruno Freire e Francisco Marcelo Rocha Ferreira acerca de uma versão preliminar do artigo. Como de praxe, a responsabilidade pelo conteúdo final do trabalho cabe inteiramente ao autor.

2 O tratamento deste ponto foge aos limites deste artigo. De qualquer forma, cabe dizer que: a) o fato de um grupo de países não constituir uma área monetária ótima não é um obstáculo à unificação monetária entre eles; e b) a proposta de que os países do Mercosul venham algum dia a ter uma moeda única, pressupõe a existência de um tempo de preparação suficientemente 
longo para que o espaço geográfico formado por eles se torne mais próximo de ser uma área monetária ótima.

3 Para algumas destas críticas ver, por exemplo, Serra (1998).

4 Para uma análise dos problemas específicos da integração financeira entre os países do Mercosul, que inclusive dá origem a uma postura cética do autor do estudo, acerca da possibilidade de futuros avanços em termos de coordenação de políticas entre os países, ver o trabalho de Abreu (1997).

5 Gazeta Mercantil, 28 de abril de 1997. Reprodução textual do jornal.

6 Tais riscos serão analisados posteriormente na seção 4 do trabalho.

7 Um dado que também é interessante citar é o crescimento das exportações totais do Mercosul para o próprio Mercosul. Esta variável, que foi de 9 \% do total das exportações - incluindo exportações para a região - por Argentina, Brasil, Paraguai e Uruguai em 1990, aumentou para $25 \%$ desse total em 1997.

8 Em outras palavras, o estabelecimento de uma meta de compromisso externo de ajuste fiscal interno visaria obter um benefício adicional de uma política que o país terá que adotar, com ou sem estabilização monetária.

9 O resultado primário do setor público - que exclui o pagamento de juros - tem piorado continuamente, desde 1994.

10 Consideramos que o euro começará inicialmente com 11 países e que ele será adotado, até o início da próxima década, por Grã-Bretanha, Suécia, Dinamarca e Grécia, sendo seguidos, depois disso, pelos 6 novos membros das economias anteriormente socialistas e cujo ingresso na UE já foi anunciado. Embora a adesão à UE e a entrada na área do euro sejam processos diferentes, é natural imaginar que a adoção deste será uma conseqüência natural daquela adesão. Entrevista à revista IstoÉ-Dinheiro, Brasil, 11 de março de 1998, página 25.

\section{Resumo}

Este artigo comenta algumas das críticas feitas à proposta de criação de uma moeda única para o Mercosul. Esclarece-se que a proposta deve ser entendida como uma meta a ser alcançada após a concretização de uma série de pré-requisitos, explica-se por que a interpretação de que a proposta só interessa à Argentina não nos parece correta e expõem-se os motivos pelos quais algumas das outras críticas, ainda que corretas, não invalidam a unificação monetária. O texto conclui com uma reflexão a respeito da necessidade de o Brasil definir que papel pretende desempenhar no contexto mundial, daqui a 15 ou 20 anos.

\section{Abstract}

This article comments on some of the criticisms made to the proposal of a currency union among the Mercosur countries. It is clarified that the proposal must be understood as a target to be achieved after fulfilling a set of requirements. Besides, it is explained why we believe that the interpretation that the proposal would only be beneficial to Argentina is wrong and why some of the other criticisms, 
even being correct, do not invalidate the monetary unification. The paper concludes with a reflection about the Brazilian necessity of defining which role the country intends to play in the world, in 15 or 20 years.

Palavras-chave: Mercosul. Integração. União monetária. Áreas monetárias ótimas. Key-words: Mercosur. Integration. Monetary union. Optimal monetary areas. 